\title{
The effect of price and production risks on optimal farm plans in Swiss dairy production considering 2 different milk quota systems
}

\author{
S. Briner ${ }^{* 1}$ and R. Fingert \\ *ETH Zürich, Agri-food \& Agri-Environmental Economics Group, CH-8092 Zürich, Switzerland \\ †Wageningen University, Agricultural Economics and Rural Policy Group, 6706 KN Wageningen, the Netherlands
}

\begin{abstract}
The amount of milk produced on Swiss dairy farms is restricted by contracts between the farmers and their marketing agent. In the past, these contracts have been calculated on a yearly base. Due to a switch in agricultural policy, these yearly contracts are currently more and more replaced by contracts calculated on a monthly base. These new contracts are assumed to restrict the flexibility of farmers to react on changes in milk price as well as on changes in fodder availability. Thus, the contract design is expected to influence farmers' ability to cope with risks and, thus, to influence the farm's gross margin variability. Applying a bioeconomic whole-farm model, the effects of price and weather risk as well as different risk-management strategies on the gross margin and the variability of the gross margin in Swiss dairy production are assessed under the 2 contract designs. We consider both risk-neutral and riskaverse behavior of farmers in our study. Results show that gross margin is slightly higher under the yearly than under the monthly contract. Variability of gross margin is also higher under the yearly than under the monthly contract. If the farmer is assumed to be risk averse, under both contracts he can reduce the coefficient of variation of the gross margin by almost $20 \%$ at opportunity costs below $1 \%$ of the gross margin. To reduce variability of gross margin under both contracts the size of the feedstock needs to be increased. This increase, however, must be considerably higher under the monthly contract than under the yearly contract. An additional risk-management strategy under a monthly contract is an increase in the area used as intensive pasture to ensure fodder availability in years with unfavorable weather. Under the yearly contract, an increase in the area used as extensive pasture is shown to be more favorable because it increases the amount of direct payments the farmer will receive. Additional restrictions in farm management due to a monthly milk contract do
\end{abstract}

Received August 26, 2012.

Accepted December 10, 2012.

${ }^{1}$ Corresponding author: briners@ethz.ch not lead to a higher variation in gross margin. However, if a farmer agrees to a monthly contract, he needs to adapt his risk-management strategies. Furthermore, our results show that farmers have to be aware that they will need additional barn capacities to reduce variation in gross margin under a monthly milk contract.

Key words: gross margin variability, milk contract, risk management, whole-farm modeling

\section{INTRODUCTION}

When managing farms, dairy producers face several sources of risk and uncertainty that they need to take into account when making decisions. For instance, variable weather conditions affect the productivity of grasslands and, subsequently, forage production. Fluctuating input and output prices as well as variable production levels (e.g., affected by herd health problems) are additional important sources of risk and uncertainty (Hardaker et al., 1997; Moschini and Hennessy, 2001). These factors directly affect farmers' incomes and can be a threat for the future of their farms. In the future, risks in agricultural production are expected to increase due to climate change and increasing volatility in agricultural markets (Meuwissen et al., 2003; Sckokai and Moro, 2005; Howden et al., 2007). In addition, government intervention in the agricultural sector can influence production and price risks by restricting management practices (e.g., banning certain agrochemicals) and by using different market-protection schemes (e.g., using import tariffs). In the dairy sector, regulation of production levels using quota systems is expected to influence farmers' income risks by limiting their managing flexibility and normal market mechanisms.

To cope with these risks and to stabilize farming income, farmers need to adapt their management plans. In dairy farming, forward contracting of milk and fodder prices, for example, are efficient and wellestablished risk-management strategies (Schmit et al., 2007). Moreover, decreasing the stocking rate and storing fodder between years to cope with unfavorable weather conditions are suitable risk-management tools (e.g., White et al., 2009). 
In addition to such on-farm risk-management measures, farmers can also reduce income risks by using financial products such as insurances (see, e.g., Bielza Diaz-Caneja et al., 2008, for an overview). For example, crop insurance can guarantee liquidity to buy additional fodder during years with unfavorable weather conditions (Bosch and Johnson, 1992). Furthermore, income insurance schemes are currently evolving in many countries (Meuwissen et al., 2003; Turvey, 2012).

In this paper, we address risk-management strategies and their interplay with policy reforms in Swiss dairy farming. This scope is motivated by the fact that dairy farming is the most important branch of production in Swiss agriculture. In 2010, 44\% of Swiss farmers produced and sold milk and dairy farming contributed to about $24 \%$ of the value of goods produced by Swiss agriculture. Dairy products are also the main export products of Swiss agriculture. However, the income risk of Swiss dairy farmers has been increasing during the last 2 decades (El Benni and Finger, 2013). For instance, the integration of a part of the Swiss milk market, which was reached with a free trade agreement for cheese between the European Union and Switzerland, led to an increased variability in milk prices. In addition, the negative correlation between price and production risk has been decreasing due to the integration of the Swiss in the European Union dairy market. This decreases the possibility of natural hedging for Swiss dairy farmers and makes on-farm risk management even more important. Implementing such risk-management strategies becomes more complicated because Swiss dairy farmers' production is restricted by milk contracts. These milk contracts are necessary because prices for dairy products, with the exception of cheese, are highly regulated (e.g., by tariffs on imported products). The resulting high price levels induce incentives for overproduction. Whereas in the past, milk production was regulated by the Federal Office of Agriculture (FOAG), the government abolished the quota system during the last $10 \mathrm{yr}$, and the amount of milk produced is now regulated privately (see e.g., Mann and Gairing, 2011, for details). Milk must now be traded through specialized marketing agencies or be sold directly to a milk processor. These marketing agencies are associations of several producers that are either independent or related to a milk processor. The law requires that contracts between farmers and milk buyer have a validity period of at least $1 \mathrm{yr}$ and that they must contain an agreement about the amount of milk delivered by the farmer and the payment system (Swiss Federal Assembly, 1998). As a result, the milk production of each farm is still restricted. If a farmer wants to produce more milk than specified by the base contract, the payment system in the contracts indicate that additional production will be compensated at a lower and more variable price because the milk has to be exported. In the past (under the government regulations), the amount of milk that could be sold under the contract was calculated on a yearly basis. In contrast, new contracts are now often based on equal monthly milk production. This is mainly due to the fact that the processing industry is interested in a stable supply of milk over the year. This change in the system is expected to reduce farmers' ability to cope with changes in their production capacity due to changing weather or milk prices.

Based on this background, the goal of this study is to analyze the relevance of different risk-management strategies in Swiss dairy farming. The focus of our analysis is the effect of production and price risks as well as the contract design (i.e., milk quota implementation) on the suitability of various risk-management strategies. We develop a bioeconomic whole-farm model that reflects a typical Swiss lowland dairy producer. Applying this model, we consider on-farm risk-management measures, such as the adaptation of land use, the adjustment of herd sizes, storage of roughage in the form of hay or silage bales, and the use of maize as a switch crop. Finally, we compare the suitability of these risk-management strategies under marketing contracts based on monthly or yearly accounting (i.e., the 2 quota systems). This modeling setup is used to answer the following research questions: (1) what are the mean and the variance of the farm-level gross margin under different assumptions for risk preferences? (2) what is the effect of the different contracts on the farmers' gross margin? and (3) do the temporal attributes of the contract influence the suitability of risk management strategies?

\section{MATERIALS AND METHODS}

To assess the effect of various risk-assessment strategies, we developed a bioeconomic whole-farm model reflecting a representative dairy farm in the Swiss lowlands. The representative farm has a size of 30 ha and is located on the Swiss Plateau where the climatic conditions allow for intensive grassland and crop production (following Briner and Finger, 2012). Our model covers grass and maize production, using weather information from an operational weather station (Wynau, $47^{\circ} 15^{\prime} \mathrm{N}$, $7^{\circ} 47^{\prime} \mathrm{E}, 422 \mathrm{~m}$ above sea level), located in the canton of Solothurn (Switzerland).

The farm represented in our model is specialized in dairy farming, with the majority of farm acreage being allocated to fodder production. This specialized farm type is of increasing relevance in Swiss agriculture after the recent reforms of the milk markets. More 
specifically, decreased government intervention allows farms to profit from economies of scale by specializing on dairy farming. The risks represented in the model include weather risks (in the form of volatile fodder production) and price risks (in the form of volatile milk prices). The model does not simulate long-term changes in the farm type (e.g., a switch to crop farming), but simulates an ex-ante 10-yr farm plan. This farm plan has a time resolution of 1 mo for decisions concerning livestock housing (the number of livestock as well as the feed mix) and 1 yr for land-use decisions. The decisions with respect to land use are made at the beginning of each year and they must hold for all possible states of nature (i.e., combinations of weather and price events). A time horizon of $10 \mathrm{yr}$ is chosen to cover the entire production cycle of a dairy cow and to reach equilibrium production states. In addition, a time horizon of more than $1 \mathrm{yr}$ is necessary to represent decisions about storing fodder across years. The monthly and annual time horizons in our model allow us to simulate tactical (within a year) and strategic (over a few years) adaptation responses to cope with weather and price risks. In the optimization of this farm plan, we assume 2 different goal functions. First, we assume farmers to maximize gross margin that is used as proxy for income. Second, we consider a risk-averse farmer who mitigates events with low gross margin.

The remainder of the methodology section is structured as follows: first, the goal functions that represent the farmer's decision-making process are introduced. Second, the activities considered in our model are presented in detail. Third, agronomic and political restrictions considered in the model as well as the data sources used are presented. Finally, the calculation of the gross margin is presented.

\section{Farmers' Decision Making}

We assume 2 different goal functions of the farmer in our analysis. First, we assume the farmer to maximize his gross margin. The calculation of gross margin allows the simulation of short- and mid-term strategies that do not need investments in new production factors (i.e., that do not affect fixed cost). In this case, changes in the income are only related to changes in the gross margin as is the case in this study. Second, we consider that a risk-averse farmer can increase his utility if he is able to reduce the variability of his gross margin. To figure out the effect of differences in risk aversion on the farm plan and on average gross margin, we consider a risk-neutral and a risk-averse farmer. Both farmers' decision-making processes are incorporated in the model by using a combined discrete stochastic programming approach. In addition, for the risk-averse farmer we use a safety-first approach (e.g., Cocks, 1968). Applying this method allows the introduction of uncertainty into coefficients of the objective function and the input-output coefficients or resource endowments. In this modeling approach, information on the probability of realizing discrete states of nature is used, which enables an unbiased use of yield and price observations. An additional advantage of discrete stochastic programming is that problems can be formulated in a linear programming framework for which powerful solving algorithms are available.

The model uses a repeated 2-stage decision problem (see also Briner and Finger, 2012). The endogenous variables optimized in stage 1 are the land-use activities - once for all states of nature in every year - and in stage 2 the purchase and sale of livestock, the feed mix, the decision about how much feed is sold and purchased, and the use of the grass (pasture, hay, or silage) and maize (grain or silage) harvested. Decisions in stage 2 are made every month and for every state of nature in a temporal dynamic framework. The outcomes of the different months are linked over the amount of feedstuff stored and the number of animals transferred from month to month. For the analysis of the results, gross margins are aggregated on a yearly base for each of the 5 states of nature, resulting in 50 different observations. In this framework, it is assumed that complete information is available about the outcome of the first-stage decision (Apland and Hauer, 1993; i.e., the outcome of the farmer's decision on land use). In a simplified representation, the decision problem based on maximizing gross margins has the following form:

$$
\max Z=\frac{1}{k} \sum_{k=1}^{5} g \mathbf{X}+m_{k} \mathbf{Y}_{k}
$$

such that

$$
\begin{gathered}
\mathbf{a X}+\mathbf{b} \mathbf{Y}_{k} \leq r ; \\
\mathbf{c}_{k} \mathbf{X}-\mathbf{d} \mathbf{Y}_{k} \geq 0 ; \\
\mathbf{X} \geq 0, \mathbf{Y}_{k} \geq 0 .
\end{gathered}
$$

To optimize the 10-yr farm plan, the framework presented in Equation 1 must be expanded by a time dimension $t$. In this equation, $Z$ is the annual gross margin at the farm level and $g$ represents the gross margin of the land-use activities (details outlined below), which are primarily dedicated to land cultivation. Gross margins at this stage are, thus, negative because no revenues from these activities are considered yet. Note, however, that the gross margins related to the 
selling of the feedstuff and maize that exceed the feeding requirements are calculated in stage $2 ; \mathbf{X}$ is the decision vector for decisions in stage 1 (land use). To ensure complete information in stage 1 , the decision vector $\mathbf{X}$ must be the same in all states of nature $k$; once a land-use decision is made, the decision is valid for all states $k$ (i.e., for all combinations of prices and crop yields in $1 \mathrm{yr}$ ).

The gross margins are designated as $m$ and $\mathbf{Y}$ is the decision vector of activities optimized in stage 2 . Decision vector $\mathbf{Y}$, which is valid only for one specific combination of yields and prices, is different in all states of nature $k$. To introduce output price variability, also gross margins $m$ differ in the different states of nature $k$. In contrast to decisions made in stage 1 , decisions made in the second stage, therefore, are optimal for only one specific state of nature. This means that every month the farmer has the possibility to adapt decisions made in stage 2 based on the outcome of the decisions made in stage 1.

An additional important part of the optimization problem are the constraints (Equations 2 to 4 ): $\mathbf{a}$ and $\mathbf{b}$ are vectors of the resource needs of the different activities that may not exceed the total available resources $r$; $c$ are the yields of the land-use activities $\mathbf{X}$ that differ in the states of nature $k$ (i.e., even if the land use is the same for all years and all states of nature, the outcome of this decision differs between years and states of nature). The aggregated yields of the land-use activities must be higher than the need for feedstuff $d$ for the activities in stage 2: the yields must be higher than the amount of fodder fed or sold minus the amount of fodder purchased on the market. This restriction is relaxed to some extent by the possibility to transfer fodder to the following decision period. Decisions about the number of animals are constrained through the fact that the production cycle of the animals span over multiple months (for details, see below) but decisions are only possible at the end of a production cycle.

In contrast to other studies [e.g., Mosnier et al. (2011) and Dorward (1999)], states of nature are not modeled in discrete classes, but discrete sets of realized yields and prices (drawn randomly) are used (see also section yield data). After the optimization process, the mean and standard deviation of the resulting 50 observations on gross margins are calculated and analyzed.

In the next step, we introduce a risk-averse farmer in the framework. For this farmer, we assume that he does not only optimize the gross margin but also considers the effect of risky events in his farm plan. In this study, we assume that these events are implemented in the optimization process using a safety-first mechanism based on the work of Roy (1952), which was used in several other studies (e.g., Robison et al., 1984; Bigman, 1996;
Haley, 2012). This safety-first rule is implemented on a level of $90 \%$ of the average gross margin. Thus, the gross margin in each year must never fall below this threshold. The limit was chosen because the average Swiss dairy farm needs $90 \%$ of its average gross margin to pay debts, for compulsory debt retirement, to pay short-term debt, and to have enough money to live [own calculations based on data derived from Mouron and Schmid (2011)].

\section{Activities}

In the first decision stage, land use on the 30 ha is optimized. The model has a choice of 3 different types of grassland (see Briner and Finger, 2012): grazed grassland, mown grassland, and mown grassland in crop rotation with maize. Each grassland type is available in 3 intensities (based on differences in fertilization levels): intensive (yield $=100 \%$ ), mid intensive (yield $=78 \%$ ), and extensive (yield $=28 \%$ ). These types of grassland use and production intensity reflect the current conditions observed in Switzerland (Dütschler-Herrmann et al., 2006). Land can also be used to grow maize for silage or grain maize and wheat. Maize can either be harvested as silage and then be used as feedstuff if the yields on grassland are too low to feed the animals or it can be sold as grain maize at the end of the year. The advantage of cultivating maize is that the farmer does not have to decide whether to harvest the maize as silage or corn until $90 \%$ of the grass has been harvested. Therefore, planting maize is a form of an on-farm riskmanagement measure. In addition, grain maize can also be used to diversify the farm portfolio. Because prices for grain maize in Switzerland are still regulated and, therefore, show very low variability (Finger and El Benni, 2012), there is no price risk in grain maize production in contrast to milk production.

The main activity considered in the second stage of the decision problem is milk production. In this step, the model chooses the optimal number of dairy cows and heifers. The production cycle of a dairy cow lasts 12 mo. In the first month of the cycle, the cow is calving and starts producing milk. In the last month of the cycle, the cow no longer produces milk. In between, the milk production capacity of the dairy cows is calculated on a monthly basis using numerical relationships provided by Kwizda et al. (1957). A cow's production period is assumed to be limited to 5 lactation periods. To represent this restriction in the model, the number of cows of the same age is reduced by $20 \%$ after each lactation period. The farmer can adjust the number of animals allowing him to react on changes in fodder production and market prices. If prices for milk drop, the farmer has the possibility to reduce the number of 
Table 1. Dairy production system ${ }^{1}$

\begin{tabular}{lr}
\hline Item & Value \\
\hline Weight of the cow $(\mathrm{kg})$ & 650 \\
Calves per year $(1 / \mathrm{yr})$ & 1 \\
Milk production $(\mathrm{kg} / \mathrm{yr})$ & 7,500 \\
Maximum number of cows in barn & 70 \\
Ratio of male/female calves & $1: 1$ \\
Age of first calving (mo) & 24 \\
\hline
\end{tabular}

${ }^{1}$ Sources: Blum et al. (2010) and own assumptions.

cows and to expand other branches of the farm, such as grain maize production, or to extensify farm cultivation, which increases the amount of direct payments he receives. However, dairy cows can only be sold at the end of the lactation period and additional cows can only be integrated in the herd just before calving (i.e., in the first month of the production cycle). Young cows can be either bought from outside the farm or raised on the farm. All male offspring are sold at the age of 2 mo. In contrast, female offspring can be sold at the age of 2 mo or raised on the farm. On-farm raised cows are assumed to calve for the first time at the age of 24 mo. However, if no additional cows are needed, heifers can be sold at the age of 24 mo. For more information about the production system, see Table 1 .

\section{Balances}

In the optimization process, the different activities are linked through the fodder and nutrient balances, which are described in more detail below.

Fodder Balance. Following the procedure described in Briner et al. (2012), feed mix is calculated endogenously in the optimization process and can be adapted on a monthly basis. Thus, for every single class of animals, for example, for cows and heifers of different ages, a feed mix is optimized. The diet has to satisfy the animals' energy and protein needs calculated for each specific animal type on a monthly basis using equations provided by Arrigo et al. (1994). This procedure considers the specific demands for preservation, milk production, gravidity, and growth. More specifically, the feed demand for preservation depends on the average liveweight of the animals each month. In addition to meeting nutrient demands, the fodder balances applied in our model also ensure that the amount of DM in the daily feed mix are within a specific range.

Fodder is supplied in different forms of roughage and concentrate. The cows can be fed grass in the form of (1) grazing pastures, (2) grass silage, and (3) ground dried hay. Following Arrigo et al. (1994), we assume that the nutrient content of grass increases if the grassland is cultivated more intensively. Maize can be conserved only in the form of silage. The cows' diet can be supplemented with various grain-based concentrates that have to be purchased on the market.

The farmer can adjust the amount of the feedstock, allowing him to react to changes in fodder production and market prices. Storing feed in bulk is, however, limited by the barn capacity of the farm. Following the usual practice, we assume that grass and maize silage are stored in silos that have a total capacity of $100 \mathrm{t}$ of DM. In addition, grass silage and hay can be stored in bales. However, producing bales negatively affects the farm's gross margin because they can be only produced by a contractor (Table 2). In contrast to storing grass silage in bulk, no capacity limitation exists for storing hay and silage in bales because it does not require a building. In addition, the farmer can sell and buy additional hay and grass silage from other farmers to bridge a gap in fodder production in years with unfavorable weather conditions [see Table 2 for details, and Agrigate (2012) for examples].

Nutrient Balance. The nutrient balance ensures that the modeled farm fulfills the cross-compliance requirements [proof of ecological performance; see El Benni and Lehmann (2010) for details], which represents a criterion for receiving direct payments in Switzerland. To fulfill the proof of ecological performance, the amount of nutrients spread may not exceed $110 \%$ of the nutrient demand of the crops and grassland. The nutrient balance in the model was calculated according to the official calculation criteria (for details see Amaudruz et al., 2003).

\section{Yield Data}

For each of the 5 possible states of nature $k$ (causing different yield levels), the grass and maize yield data are calculated for $10 \mathrm{yr}$ (see Table 2 for the average and the standard deviation and Table A1 in the Appendix for the entire data set). Grassland yields for this study region are taken from Finger and Calanca (2011), who provide information on distributions of grassland yields under various nitrogen fertilization regimens. Maize yields are based on Lehmann et al. (2012), using the same setup as for deriving grassland yields. This procedure ensures that the yield distributions of grassland and maize refer to the same study region and the same time horizon. In our model, the grassland and maize yields are randomly chosen from available yield observations provided by these studies. To account for correlations between maize and grassland yields, maize yields are ranked in the same order as grassland yields. Thus, high- and low-yield events, respectively, for grass and maize production are assumed to occur jointly. 
Table 2. Input parameters

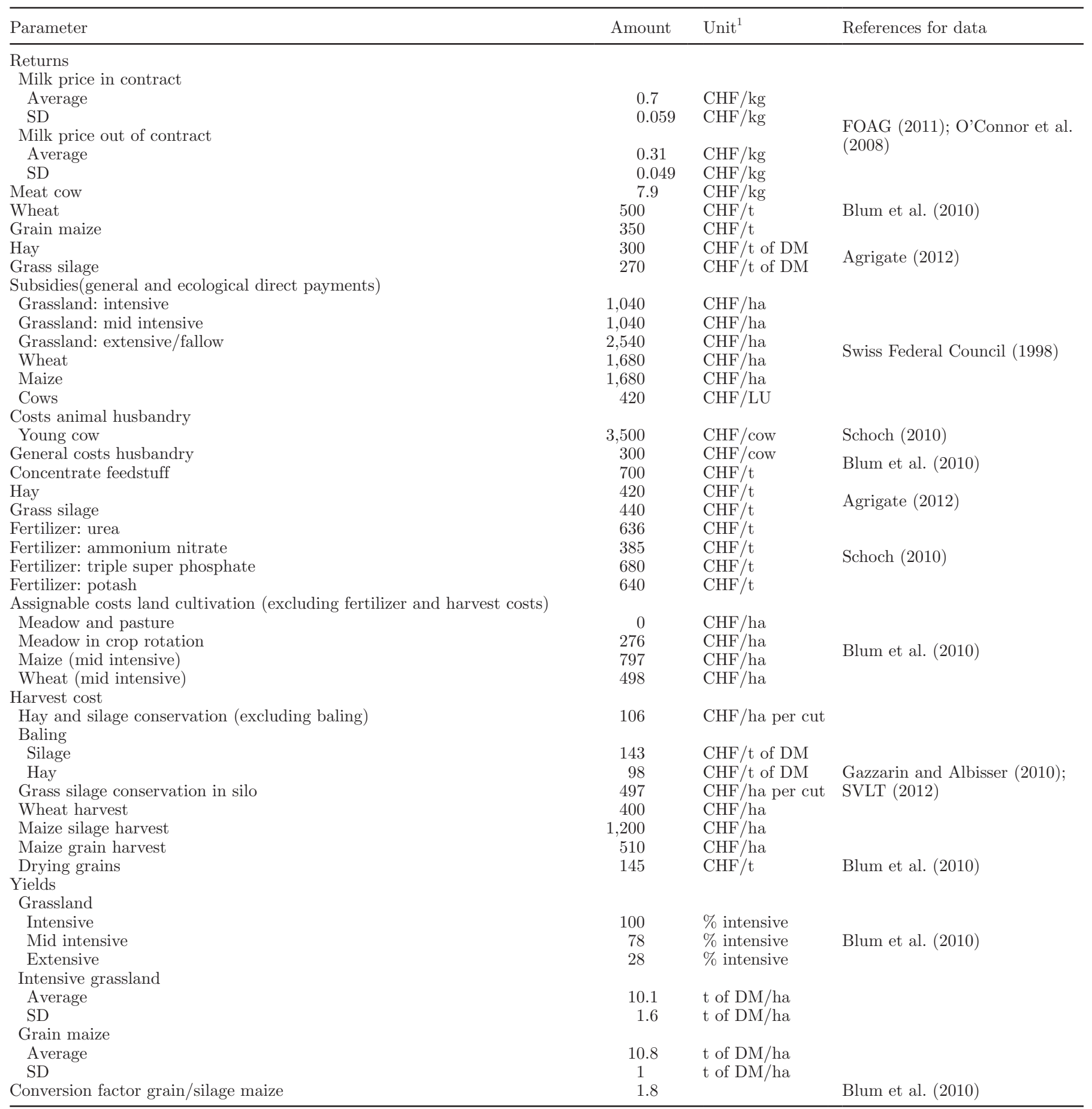

${ }^{1} \mathrm{CHF}=$ Swiss franc; LU $=$ livestock unit.

\section{Price Data}

In our analysis, we focus on the influence of output price volatility on optimal farm decisions. Because crop prices in Switzerland are highly regulated by the government, their price volatility is rather low (e.g., Finger and El Benni, 2012). In contrast, Swiss dairy production is partly integrated in European markets (due to a free-trade agreement for cheese) and milk prices are, thus, expected to exhibit larger volatilities. Thus, in the current study, only the price of milk is assumed to vary. There are 2 different prices (and price volatilities) 
for milk: one price for milk sold inside the contract and one for milk sold outside the contract (if the amount produced exceeds the specified threshold). The price distribution for milk sold inside the contract used in our model is based on past Swiss milk prices. The data for the calculation are based on official price statistics published by the FOAG (FOAG, 2011). Intraannual price development for milk in Switzerland follows a seasonal pattern, with low prices in winter and higher prices in summer. We account for this pattern in the model by setting the base for milk prices using average monthly prices from 2004 to 2011 . The same data are used to calculate the interannual variation of the prices, which is estimated as the standard deviation. The price distribution for milk sold outside the contract used in our model is based on O'Connor et al. (2008), who provide mean and variability of global market prices for milk powder and butter. For the global market prices, no regular interannual pattern was assumed; the base milk price was the same for all months.

Using these data, 5 sets of 10 yr of monthly deviations from the average milk price are drawn randomly from a normal distribution using the information on price distributions that are then added to the average monthly prices. For each of the 5 states of nature, a set of monthly prices for milk sold in- and outside the contract is implemented in the model. (Details of the price distributions are available upon request from the authors.)

\section{Calculation of Gross Margin}

With exception of prices for milk the gross margin calculation is based on price data for the year 2010 (see Table 2 for details; the derivation of the milk prices follows a different approach that has been described in the previous section). The calculation of the returns differs between 2 scenarios representing monthly and yearly contracts, respectively. Under the yearly contract, the amount of milk sold to the higher national price is limited to $300,000 \mathrm{~kg}$. This amount has been chosen, because there is a fast-increasing number of farms of that size (Muller, 2011). If a farmer wants to deliver more milk, he will be paid the global market price valid at the end of the respective year. Under the monthly contract, delivery of milk at the higher contract price is restricted to one-twelfth of the annual quantity in each month. If a farmer wants to deliver more, the global market price of the respective month is paid out.

As costs, we consider that housing animals requires fixed costs per animal such as veterinary costs. Furthermore, fodder costs depend on the feed mix used. For instance, producing the feedstock on the farm involves machinery costs for cutting the grass, except for the case that the land is grazed. These machinery costs depend on the production intensity, as it influences the number of times the meadow is mowed. Additional costs are incurred if a contractor has to make hay or silage bales or if the farmer has to purchase artificial fertilizer. Additional costs arise for protecting plants and spreading manure. Details on the calculation of the gross margin are presented in Table 2.

\section{RESULTS}

The design of the dairy contract has an effect on the average and variability of the gross margin. We find that the average gross margin is about $1 \%$ higher under the yearly contract than under the monthly contract (Table 3 ). The additional gross margin is increased because under the yearly contract, the model uses the flexibility of the contract to plan production anticyclically (more milk is produced in the fall, when milk prices are high, and less in the spring, when milk prices are low). Under this contract, the amount of milk produced per month follows a seasonal pattern, whereas under the monthly contract, the amount of milk produced per month remains constant (see Figure 1). This higher gross margin under the annual contract regimen mainly stems from the fact that the seasonal production pattern takes advantage of higher milk prices in the fall. More specifically, the annual revenues from selling milk are 5,600 Swiss francs higher under the yearly than under the monthly contract regimen. However, part of this money must compensate for higher costs for replacing old cows, which is more challenging under the yearly contract. The anticyclical production pattern under the yearly contract implies that most cows are in the same stage of their production cycle (i.e., that most cows calve during a short time at the end of the summer). In contrast, under a monthly contract, cows need to calve constantly during the year, such that a constant amount of milk can be delivered. This demands that in each month, approximately the same number of cows must be in each stage of the production cycle.

Due to the fact that under a yearly contract most cows calve at the end of the summer, the highest fodder demand still occurs during the vegetative growth period. In contrast, under a monthly contract, calving is spread regularly throughout the year, with increasing feedstock demand in the winter. Thus, the amount of feedstock required over the winter is larger under the monthly than under a yearly contract. This causes higher costs for fodder conservation. Thereby, the total amount of fodder produced does not differ between the 2 contract scenarios because the average milk production per year only differs slightly (i.e., also the average number of cows housed in the contracts only differs by 
Table 3. Effect of the different scenarios on key parameters of the respective farm plan, including the mean and standard deviation of the gross margin $^{1}$

\begin{tabular}{|c|c|c|c|c|}
\hline \multirow[b]{2}{*}{ Item } & \multicolumn{2}{|c|}{ Yearly contract } & \multicolumn{2}{|c|}{ Monthly contract } \\
\hline & SQ & RA & SQ & RA \\
\hline \multicolumn{5}{|l|}{ Yearly income } \\
\hline Maximum (CHF) & 368,439 & 354,886 & 356,626 & 339,033 \\
\hline Minimum (CHF) & 217,322 & 258,000 & 229,604 & 258,000 \\
\hline Average (CHF) & 286,767 & 286,349 & 284,138 & 283,574 \\
\hline $\mathrm{SD}(\mathrm{CHF})$ & 31,089 & 25,179 & 26,265 & 20,992 \\
\hline $\mathrm{CV}$ & 0.11 & 0.09 & 0.09 & 0.07 \\
\hline \multicolumn{5}{|l|}{ Number of cows at the end of year } \\
\hline Minimum & 45.74 & 46.4 & 48.96 & 48.37 \\
\hline Maximum & 68.35 & 68.3 & 64.5 & 62.47 \\
\hline Average & 58.98 & 59.03 & 57.96 & 57.88 \\
\hline \multicolumn{5}{|l|}{ Feedstock at the end of year } \\
\hline Minimum (dt of DM) & 398 & 444 & 470 & 561 \\
\hline Maximum (dt of DM) & 995 & 1,372 & 1,240 & 2,186 \\
\hline Average (dt of DM) & 714 & 733 & 783 & 870 \\
\hline \multicolumn{5}{|l|}{ Trade in roughage } \\
\hline Sold (dt of DM) & 0 & 0 & 0 & 0 \\
\hline Purchased (dt of DM) & 0 & 0 & 0 & 0 \\
\hline \multicolumn{5}{|l|}{ Average land use } \\
\hline Pasture intensive (ha) & 14.63 & 14.55 & 14.29 & 14.45 \\
\hline Pasture medium intensive (ha) & 0 & 0 & 0 & 0 \\
\hline Pasture extensive (ha) & 1.85 & 1.91 & 1.91 & 1.9 \\
\hline Wheat (ha) & 2.62 & 2.65 & 2.8 & 2.74 \\
\hline Maize (ha) & 10.73 & 10.77 & 10.87 & 10.79 \\
\hline Fallow (ha) & 0.17 & 0.13 & 0.17 & 0.16 \\
\hline
\end{tabular}

${ }^{1} \mathrm{SQ}=$ decision without risk aversion; $\mathrm{RA}=$ decision under risk aversion; $\mathrm{CHF}=$ Swiss francs.

$1.4 \%)$. This small difference is caused by the considerable difference between the prices for milk sold inside and outside the contract that makes selling milk outside the contract generally unprofitable. The amount of milk sold outside the contract, thus, is very low under both regimens: $4,947 \mathrm{~kg}$ per year under the yearly contract and 2,658 $\mathrm{kg}$ per year under the monthly contract.

We find the variability in the gross margin to be higher under the yearly contract. More specifically, the coefficient of variation is $22 \%$ higher under the yearly contract than under the monthly contract if the farmer is risk neutral. If the farm plan is adapted for a riskaverse farmer (Table 3), the standard deviation of the gross margin decreases by $19 \%$ under the yearly contract and by $20 \%$ under the monthly contract. This causes a decrease in the coefficient of variation of the gross margin by 18 and $22 \%$ under the yearly and monthly contract, respectively. Our results show that this reduction in variability causes very low opportunity costs. Assuming risk-averse behavior implies a reduction of the average gross margin under both contracts by less than $1 \%$. To reach this (cheap) reduction in gross margin variability, different risk-management measures are implemented by the risk-averse dairy farmer: our results show that the feedstock needs to be increased if variability of the gross margin shall be reduced. Whereas under the yearly contract a $3 \%$ increase, on average, is optimal if accounting for risk aversion, the feedstock is increased by $11 \%$ under the monthly contract. The feedstock stored by the farmer at the end of the year is, at a minimum, $561 \mathrm{dt}$ of DM under the monthly contract, which is $26 \%$ higher than the minimum storage amount indicated under the yearly contract.

Additional risk-management strategies differ between the 2 contracts. To ensure that enough fodder is always available in the stock, the risk-averse farmer under the monthly contract slightly increases the area allocated to intensive fodder production (i.e., intensively used pasture and maize for silage) compared with the riskneutral farmer. Fodder produced in excess - in years with good weather conditions - is then sold on the fodder market. Compared with the risk-neutral farmer, the amount of fodder sold on the market is $12 \%$ higher if the farmer is risk averse. Under the monthly contract, the risk-averse farmer also raises $9 \%$ less young cows for replacement of old cows on the farm than the riskneutral farmer. Because the amount of milk produced must be the same to fulfill the quota, the risk-averse farmer buys more young cows on the market. This gives him additional flexibility because he has to house fewer heifers, giving him an additional margin for fodder allocation.

In contrast, under the yearly contract, the risk-averse farmer reduces the land allocated to intensive fodder 

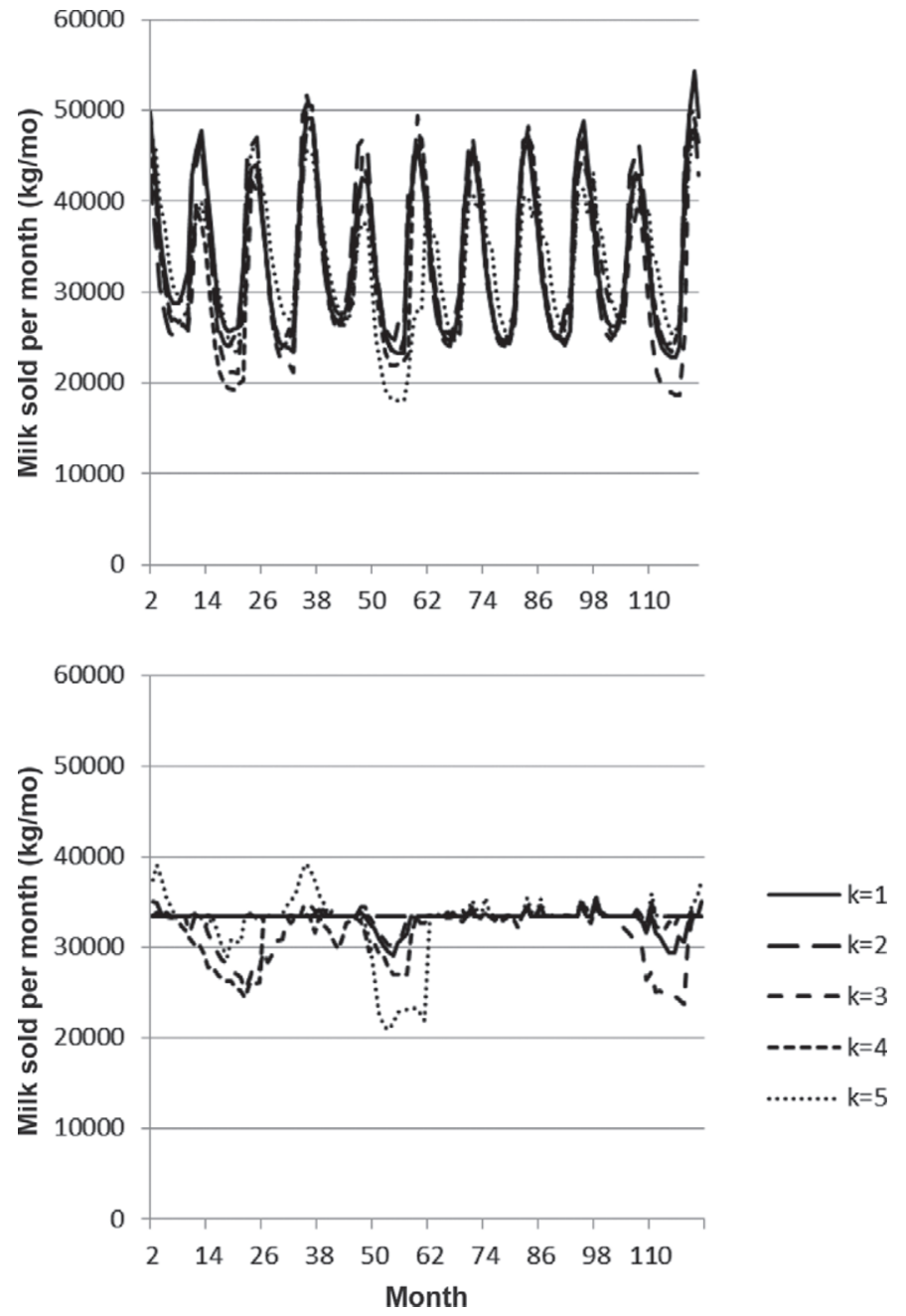

Figure 1. Milk sold per month by a risk neutral farmer under a yearly (top) and a monthly contract (bottom) during the $10 \mathrm{yr}$ of the farm plan for each of the 5 states of nature $(\mathrm{k})$.

production and increases the amount of extensively used land and land used for wheat production. For the extensively used land, the farmer receives a stable amount of direct payments from the government (see Table 2), generating a stable source of income. The increase in wheat production also decreases variability of the gross margin because for wheat, the farmer receives a stable price. In contrast to the yearly contract, under the monthly contract, the number of heifers that is optimally raised on the farm does not differ if a farmer is risk neutral or risk averse (i.e., the number of cows that are purchased on the market is the same).

The use of maize as a switch crop plays a minor role under both contracts. Under both contracts, almost all the land allocated to maize production is used for silage production. Under each contract maize is harvested for grain production only once in 50 observations.

\section{DISCUSSION}

Swiss dairy farmers face a considerable amount of risk. In the optimal farm plan the farm-level gross margin for a risk-neutral producer has a coefficient of variation of 0.11 . Because a large share of structural costs such as debts and rent need to be paid irrespective of the level of the gross margin, we expect that the coefficient of variation of income (which has not been considered in our study) will be even higher than the coefficient of variation of the gross margin. Nevertheless, in an international comparison, these values are rather low. For instance, Chang et al. (2008) showed that the income of dairy farms in New York has a coefficient of variation of between 0.23 and 0.26 . This difference may be caused by the rather large share of direct payments that provide a risk-free contribution to the gross margin and because parts of the market for milk are still protected from foreign competition, which decreases input price volatility (e.g., Finger and Lehmann, 2012). In addition, dairy farming in Switzerland focuses more on roughage compared with dairy farming in other countries. The use of concentrate feed is very limited mainly because of high tariffs that increase the price of concentrate feed. Thus, we did not consider the price variability of these inputs in our model. Due to the high price variability of concentrate feed, however, intensive dairy farmers are expected to face higher income risks (e.g., Wilson et al., 1988; Schmit et al., 2001). If tariffs for concentrate in the future decrease, the use of concentrate feed instead of roughage may increase also in Swiss agriculture. Then, the effect of feed prices on the variability of the gross margin also could become relevant for Swiss farmers.

A farm plan based on a yearly contract on average indicates higher gross margins than on a monthly contract. Under a yearly contract, the optimal farm plan shows anticyclical production patterns to profit from high milk prices in the fall. However, this leads to high demand for labor in the late summer, as then most of the cows will calve. The advantage of the yearly contract, therefore, can be exploited only if enough labor is available during this time of year. In contrast, if the contract is based on a monthly regimen, the labor demand is constant throughout the year, however, with peaks of labor demand during the summer.

Another disadvantage of monthly contracts is the demand for more feedstock for the cows in the winter and spring. For a farm with limited barn capacity, this can become a problem because additional investments are necessary to enlarge capacity. Solutions include reducing the herd size or purchasing additional roughage on the market at the end of the winter. Both solutions would further reduce the profitability of dairy farming. 
Under a yearly contract, the variability of the gross margin in the farm plan is higher than under a monthly contract. Thus, the additional flexibility under yearly contracts does not necessarily lead to decreased variability in gross margin. At least a share of this higher variability of gross margin may be associated with explicit decisions made by the farmer that lead to a lower gross margin in one specific year but an even higher increase in a following year. Under the monthly contract, such management decisions are limited because the farm needs to produce a constant flow of milk to fulfill the quota. This is necessary because the gross margin per hectare is higher for milk production than for crop production. However, this is the case only if the milk can be sold at the higher contract price.

Our results showed that gross margin variability can be reduced at a relatively small cost. Optimal risk management strategies are only partly the same under the 2 contract regimens. The most important riskmanagement strategy under both contracts is increasing the feedstock. Whereas under the monthly contract an additional strategy involves increasing the area used for fodder production per cow, under a yearly contract diversification of land use is more beneficial. This diversification brings either a higher level of direct payments in the case of extensively used meadows or more stable revenue in the case of wheat production. Under both contract regimens, these management strategies provide a cheap opportunity to reduce the variability of the gross margin. Thus, the costs for reducing the coefficient of variation by approximately $20 \%$ are less than $1 \%$ of the total gross margin. This is in contrast to the results of other studies. For instance, Mosnier et al. (2011) showed that a decrease in the coefficient of variation by between 56 and $73 \%$ caused a loss in the average gross margin of $2 \%$ for suckler cow production in France. This difference may be caused by a slight overestimation of the flexibility of the farmers in our model, as decisions about herd size are made in stage 2 (i.e., at a point in time when yields of pastures and maize already are known). In reality, the farmer has to make at least some of these decisions without this knowledge. In contrast to our study, Flaten and Lien (2007) found that risk aversion had no effect on the farm plan of a Norwegian organic dairy farm. This difference could be explained by the different goal functions used: utility-efficient programming by Flaten and Lien (2007) and a safety-first mechanism in the current study. Levy and Levy (2009) and Arriaza and GómezLimón (2003) found that when only the safety-first mechanism was used, the implications of risk aversion for behavior were overestimated. Levy and Levy (2009), therefore, suggest combining the safety-first approach with an expected utility approach in a weighted-goal function. However, this approach requires more information about the farmer's risk aversion and, therefore, ignores one of the main advantages of the approach applied in the current study.

We have explicitly considered yield risk (i.e., volatility in productivity levels) and price risks in our model. This choice was motivated by the observation that yield and price risks play a role in Swiss dairy farming, but price risks are the most important source of revenue volatility (El Benni and Finger, 2013). In agreement with dairy farmers in other European countries, Swiss farmers often perceive price risk as one of the most important sources of risk (e.g., Meuwissen et al., 2001; Schaper et al., 2008; European Commission, 2011). However, Swiss farmers perceive production risks to be almost as important as price risks (Schaper et al., 2008).

With the exception of the temporal dynamic herd composition, farm plans do not differ much under a monthly and a yearly contract. This similarity is mainly caused by the fact that under both contracts, it must be the goal for farmers to produce the amount of milk that is sellable under the high price but not more. Thus, there must be, on average, the same number of animals available on the farm, which again constrains the flexibility in land use because, in total, the same amount of fodder is needed under both contracts. We expect farm plans to differ more if the model would consider that the performance of the animals is highly variable. For example, diseases or other factors stressing the cows can affect their performance and their daily milk production. Along these lines, animal diseases are perceived as a significant source of risk by Swiss dairy farmers (Schaper et al., 2010). In the future, this challenge will probably become even larger because climate change may affect the health of cows causing higher variability in their performance (Kadzere et al., 2002; Fuhrer and Calanca, 2012).

Moreover, farmers may also aim at mitigating gross margin variability to keep their farms running (e.g., Greiner et al., 2009; Schaper et al., 2010). To investigate the influence of risk aversion on farmers' optimal management decisions, we consider in addition to a risk-neutral farmer also a risk-averse decision maker. The consideration of both risk-neutral and risk-averse behavior may represent the heterogeneity of real farm plans for risk preferences among farmers (e.g., Rosenzweig and Binswanger, 1993).

\section{CONCLUSIONS}

The design of the milk contract has an effect on dairy farming profitability and gross margin risk associated with farming. A yearly contract, in general, is more 
favorable because it provides a higher income and demands less feedstock. If accounting for risk aversion, we find an increase in feedstock to be a useful risk management option under both contract designs. However, other risk management options, such as adaptation in land use or adapted choice of the size of the herd, differ between the 2 contract designs. The modeling approach presented here does not simulate farmers' actual behavior but it yields a normative farm plan. This approach is based on neoclassical economics [Buysse et al., 2007; i.e., it assumes decision makers to make decisions in a way that maximizes their profits considering the limited availability of different resources; see, e.g., Fairweather and Keating (1994) and Barbieri and Mahoney (2009) for discussions]. The interpretation of the results, therefore, must be that farmers will maximize their gross margin if they follow this farm plan. To simulate farmers' actual behavior, it will be necessary to extend the model in a way that takes differences between the assumed and the actual weather into account as, for example, Mosnier et al. (2011) did for simulation of the decisions of suckler cow farmers in France. Such future modeling approaches may also consider nonrational behavior of decision makers (e.g., Mack et al., 2011) to take into account that gross margin optimization is only one of the farmers' goals (e.g., Greiner et al., 2009). As mentioned above, climate change will have an effect on performance of the cows and subsequently will affect variability of the farm's gross margin. The next steps of this research should, thus, integrate the effect of the variability in cow performance, including the cows' reactions to heat stress, on productivity. In addition, this work merely focused on the current state of the Swiss dairy market. Future work should also consider additional scenarios for the Swiss dairy market (e.g., for the case that full integration into the dairy market of the European Union will further increase price volatility).

\section{ACKNOWLEDGMENTS}

The authors gratefully acknowledge and appreciate the help of Niklaus Lehmann providing maize yield data. The article is a contribution to the activities of the National Centre of Competence in Research on Climate (NCCR Climate, Bern, Switzerland), supported by the Swiss National Science Foundation (Bern Switzerland), and to the research project MOUNTLAND, supported by the Competence Center Environment and Sustainability (CCES, Zurich, Switzerland) of the Eidgenössische Technische Hochschule (ETH) domain.

\section{REFERENCES}

Agrigate. 2012. Agrigate, erfolgreicher bauern. Accessed Jan. 26, 2012. http://www.agrigate.ch.
Amaudruz, M., R. Morier, A. Zimmermann, S. Hauser, H. Schüpbach, A. Übersax, V. Kessler, and L. Nyfenegger. 2003. Wegleitung Suisse-Bilanz. Landwirtschaftliche Beratungszentrale Lindau LBL, Eschlikon, Switzerland.

Apland, J., and G. Hauer. 1993. Discrete stochastic programming: Concepts, examples and a review of empirical applications. Staff Papers 13793. University of Minnesota, Department of Applied Economics, Minneapolis.

Arriaza, M., and J. A. Gómez-Limón. 2003. Comparative performance of selected mathematical programming models. Agric. Syst. 77:155-171.

Arrigo, Y., C. Chaubert, R. Daccord, I. Egger, H. Gerber, D. Guidon, F. Jans, J. Kessler, E. Lehmann, J. Morel, A. Münger, M. Rouel, U. Wyss, B. Jeangros, and J. Lehmann. 1994. Fütterungsempfehlungen und Nährwerttabellen für Wiederkäuer. Eidgenössische Forschungsanstalt für viehwirtschaftliche Produktion, Posieux, Switzerland.

Barbieri, C., and E. Mahoney. 2009. Why is diversification an attractive farm adjustment strategy? Insights from Texas farmers and ranchers. J. Rural Stud. 25:58-66.

Bielza Diaz-Caneja, M., C. G. Conte, C. Dittmann, J. Gallego Pinilla, and J. Stroblmair. 2008. Agricultural Insurance Schemes. European Commission, Joint Research Center (JRC) Institute for the Protection and Security of Citizens, Ispra, Italy.

Bigman, D. 1996. Safety-First criteria and their measures of risk. Am. J. Agric. Econ. 78:225-235.

Blum, A., M. Boessinger, M. Buchmann, J. Hanhart, U. Honegger, R. Künzler, F. Sutter, M. Leumann, P.Amsler, F. Baudraz, and P. Droz. 2010. Deckungsbeiträge - Ausgabe 2010. Agridea, Eschikon, Switzerland.

Bosch, D. J., and C. J. Johnson. 1992. An evaluation of risk management strategies for dairy farms. Southern J. Agric. Econ. 12:173182.

Briner, S., and R. Finger. 2012. Bio-economic modelling of decisions under yield and price risk for suckler cow farms. Paper no. 122547 in Proc. 123rd EAAE Seminar "Price Volatility and Farm Income Stabilisation," Dublin, Ireland. European Association of Agricultural Economists, The Hague, the Netherlands.

Briner, S., M. Hartmann, R. Finger, and B. Lehmann. 2012. Greenhouse gas mitigation and offset options for suckler cow farms: An economic comparison for the Swiss case. Mitigation and Adaptation Strategies for Global Change 17:337-355.

Buysse, J., G. Van Huylenbroeck, and L. Lauwers. 2007. Normative, positive and econometric mathematical programming as tools for incorporation of multifunctionality in agricultural policy modelling . Agric. Ecosyst. Environ. 120:70-81.

Chang, H.-H., R. N. Boisvert, and L. W. Tauer. 2008. Explaining changes in the distribution of annual dairy farm income over time. In Proc. American Agricultural Economics Association Annual Meeting, Orlando, FL.

Cocks, K. D. 1968. Discrete stochastic programming. Manage. Sci. 15:72-79.

Dorward, A. 1999. Modelling embedded risk in peasant agriculture: Methodological insights from northern Malawi. Agric. Econ. 21:191-203.

Dütschler-Herrmann, A., P. Stoll, H. Wiedmer, A. Schneider, R. Lüchinger, A. Eliker, H.-U. Tagmann, O. Ziegler, L. Keller, and B. Tanner. 2006. Pflanzen und Tiere 2006. Wirz Verlag, Basel, Switzerland.

El Benni, N., and R. Finger. 2013. Gross revenue risk in Swiss dairy farming. J. Dairy Sci. 96:936-948.

El Benni, N., and B. Lehmann. 2010. Swiss agricultural policy reform: Landscape changes in consequence of national agricultural policy and international competition pressure. Pages 73-94 in Globalisation and Agricultural Landscapes: Change Patterns and Policy trends in Developed Countries. J. Primdahl, and S. Swaffield, ed. Cambridge University Press, Cambridge, UK.

European Commission. 2001. Risk Management Tools for EU Agriculture. Working Document of the European Commission. Agricultural Directorate-General, Brussels, Belgium. 
Fairweather, J. R., and N. C. Keating. 1994. Goals and management styles of New Zealand farmers. Agric. Syst. 44:181-200.

FOAG (Federal Office for Agriculture). 2011. Marktbericht Milch. Accessed Jan. 26, 2012. http://www.blw.admin.ch/ dokumentation/00844/01044/01080/index.html?lang=de.

Finger, R., and P. Calanca. 2011. Risk management strategies to cope with climate change in grassland production: An illustrative case study for the Swiss Plateau. Reg. Environ. Change 11:935-949.

Finger, R., and N. El Benni. 2012. A note on price risks in Swiss crop production-Empirical results and comparisons with other countries. Yearbook Socioeconomics Agric. 2012:131-153.

Finger, R., and N. Lehmann. 2012. The influence of direct payments on Farmers' hail insurance decisions . Agric. Econ. 43:343-354.

Flaten, O., and G. Lien. 2007. Stochastic utility-efficient programming of organic dairy farms. Eur. J. Oper. Res. 181:1574-1583.

Fuhrer, J., and P. Calanca. 2012. Klimawandel beeinflusst das Tierwohl bei Milchkühen. Agrarforschung Schweiz 3:132-139.

Gazzarin, C., and G. Albisser. 2010. ART-Bericht 733-Maschinenkosten 2010. Agroscope Reckenholz-Tänikon ART, Ettenhausen, Switzerland.

Greiner, R., L. Patterson, and O. Miller. 2009. Motivations, risk perceptions and adoption of conservation practices by farmers. Agric. Syst. 99:86-104.

Haley, M. R. 2012. Generalized safety first and the planting of crops. Appl. Econ. Lett. 19:511-515.

Hardaker, J. B., R. B. M. Huirne, and J. R. Anderson. 1997. Coping with Risk in Agriculture. CAB International, Oxon, UK.

Howden, S. M., J.-F. Soussana, F. N. Tubiello, N. Chhetri, M. Dunlop, and H. Meinke. 2007. Adapting agriculture to climate change. Proc. Natl. Acad. Sci. USA 104:19691-19696.

Kadzere, C. T., M. R. Murphy, N. Silanikove, and E. Maltz. 2002. Heat stress in lactating dairy cows: A review. Livest. Prod. Sci. 77:59-91.

Kwizda, R., E. Hslpler, and N. Teufelhart. 1957. Laktationsfaktoren zur Bestimmung der Milchleistung. Bodenkultur 9:335-356.

Lehmann, N., R. Finger, and T. Klein. 2012. Modeling complex crop management-plant interactions in potato production under climate change. Pages 349-354 in Operations Research 2011 Proc. D. Klatte, H.-J. Lüthi, and K. Schmedders, ed. Springer, Berlin, Germany.

Levy, H., and M. Levy. 2009. The safety first expected utility model: Experimental evidence and economic implications. J. Bank. Finance 33:1494-1506.

Mack, G., A. Möhring, A. Zimmermann, M.-P. Gennaio, S. Mann, and A. Ferjani. 2011. Farm entry policy and its impact on structural change analysed by an agent-based sector model. In Proc. EAAE 2011 Congress: Change and Uncertainty Challenges for Agriculture, Food and Natural Resources, Zurich, Switzerland. ETH Zurich, Zurich, Switzerland.

Mann, S., and M. Gairing. 2011. Post milk quota experiences in Switzerland. EuroChoices 10:16-21.

Meuwissen, M. P. M., R. B. M. Huirne, and J. B. Hardaker. 2001. Risk and risk management: An empirical analysis of Dutch livestock farmers. Livest. Prod. Sci. 69:43-53.

Meuwissen, M. P. M., R. B. M. Huirne, and J. R. Skees. 2003. Income insurance in European agriculture. EuroChoices 2:12-17.

Moschini, G., and D. A. Hennessy. 2001. Chapter 2: Uncertainty, risk aversion, and risk management for agricultural producers. Pages 88-153 in Handbook of Agricultural Economics. B. L. Gardner, and G. C. Rausser, ed. Elsevier, Amsterdam, the Netherlands.

Mosnier, C., J. Agabriel, M. Lherm, and A. Reynaud. 2011. On-farm weather risk management in suckler cow farms: A recursive dis- crete stochastic programming approach. Pages 137-154 in BioEconomic Models Applied to Agricultural Systems. G. Flichman, ed. Springer, München, Germany.

Mouron, P., and D. Schmid. 2011. Grundlagenbericht 2010: Zentrale Auswertung von Buchhaltungsdaten. Agroscope Reckenholz Tänikon ART, Tänikon, Switzerland.

Muller, T. 2011. Auswertung der Daten über die Milchproduktion. Federal Office for Agriculture, Bern, Switzerland.

O'Connor, D., M. Keane, and E. Barnes. 2008. Managing price risk in a changing policy environment: The case of the EU dairy industry. In Proc. 108th EAAE Seminar "Income Stabilisation in a Changing Agricultural World: Policy and Tools," Warsaw, Poland Editorial House Wies Jutra, Warsaw, Poland.

Robison, L. J., P. J. Barry, J. B. Kliebenstein, and G. F. Patrick. 1984. Risk attitudes: Concepts and measurement approaches. Pages 1130 in Risk Management in Agriculture. P. J. Barry, ed. Iowa State University Press, Ames.

Rosenzweig, M. R., and H. P. Binswanger. 1993. Wealth, weather risk and the composition and profitability of agricultural investments. Econ. J. 103:56-78.

Roy, A. D. 1952. Safety first and the holding of assets. Econometrica 20:431-449.

Schaper, C., A. Spiller, and L. Theuvsen. 2010. Risikoneigung und Risikoverhalten von Milcherzeugern: Eine Typologisierung. Yearbook Socioecon. Agric. 6:157-193.

Schaper, C., C. Wocken, K. Abeln, B. Lassen, S. Schierenbeck, A. Spiller, and L. Theuvsen. 2008. Risikomanagement in Milchviehbetrieben: Eine empirische Analyse vor dem Hintergrund der sich ändernden EU-Milchmarktpolitik. Schriftenreihe der Landwirtschaftlichen Rentenbank 23:135-185.

Schmit, T. M., R. N. Boisvert, and L. W. Tauer. 2001. Measuring the financial risks of New York dairy producers. J. Dairy Sci. 84:411-420.

Schmit, T. M., H.-H. Chang, R. N. Boisvert, and L. W. Tauer. 2007. Quantifying the contributions to dairy farm business risk: Implications for producer's risk management strategies. Cornell University, Ithaca, NY.

Schoch, H. 2010. Preiskatalog. Agridea, Eschikon, Switzerland.

SVLT (Schweizerischer Verband für Landtechnik). 2012: Maschinenkosten. Accessed Jan. 26, 2012. http://www.agrartechnik.ch/ index.cfm?parents_id $=836$.

Sckokai, P., and D. Moro. 2005. Modelling the impact of the CAP reform on farm investments. In Proc. XI EAAE Congress "The Future of Rural Europe in the Global Agri-Food System," Copenhagen, Denmark. Food, Resource and Economic Institute, Frederiksberg, Denmark.

Swiss Federal Assembly. 1998. Bundesgesetz über die Landwirtschaft. Accessed Oct. 19, 2012. http://www.admin.ch/ch/d/sr/910_1/ index.html.

Swiss Federal Council. 1998. Verordnung vom 7. Dezember 1998 über die Direktzahlungen an die Landwirtschaft. Accessed Jan. 26, 2012. http://www.admin.ch/ch/d/sr/c910_13.html.

Turvey, C. G. 2012. Whole farm income insurance. J. Risk Insur. 79:515-540.

White, T. D., H. G. Moodie, T. A. Payne, M. A. Wedderburn, and N. Botha. 2009. Increasing on-farm resilience to adverse weather events: A Northland case study. Proc. New Zeal. Grassl. Assoc. 71:21-24.

Wilson, P. N., T. R. Luginsland, and D. V. Armstrong. 1988. Risk perceptions and management responses of Arizona dairy producers. J. Dairy Sci. 71:545-551. 
BRINER AND FINGER

\section{APPENDIX}

Table A1. Grassland and maize yields of the different states of nature $(k)$

\begin{tabular}{|c|c|c|c|c|c|c|c|c|c|c|}
\hline \multirow[b]{3}{*}{ Year } & \multicolumn{5}{|c|}{ Grassland (dt/ha) } & \multicolumn{5}{|c|}{ Maize (dt/ha) } \\
\hline & \multicolumn{5}{|c|}{$k$} & \multicolumn{5}{|c|}{$k$} \\
\hline & 1 & 2 & 3 & 4 & 5 & 1 & 2 & 3 & 4 & 5 \\
\hline 1 & 111 & 105 & 107 & 110 & 114 & 114 & 111 & 106 & 113 & 120 \\
\hline 2 & 106 & 115 & 83 & 83 & 83 & 105 & 117 & 96 & 102 & 101 \\
\hline 3 & 108 & 110 & 91 & 111 & 115 & 107 & 112 & 104 & 116 & 121 \\
\hline 4 & 110 & 114 & 115 & 94 & 120 & 108 & 112 & 123 & 105 & 127 \\
\hline 5 & 80 & 89 & 84 & 71 & 56 & 100 & 110 & 102 & 75 & 83 \\
\hline 6 & 111 & 117 & 94 & 107 & 114 & 110 & 118 & 105 & 107 & 118 \\
\hline 7 & 110 & 114 & 110 & 94 & 91 & 108 & 114 & 108 & 103 & 115 \\
\hline 8 & 105 & 120 & 107 & 105 & 105 & 102 & 119 & 107 & 106 & 115 \\
\hline 9 & 120 & 94 & 111 & 114 & 115 & 115 & 111 & 120 & 127 & 124 \\
\hline 10 & 88 & 82 & 56 & 90 & 84 & 102 & 95 & 88 & 103 & 105 \\
\hline
\end{tabular}

